\title{
Interpretation of complex demand pacemaker arrhythmias
}

\author{
S. Serge Barold, John J. Gaidula, Richard L. Banner, George I. Litman, \\ and Sidney Goldstein \\ From the Department of Medicine, Highland Hospital, Genesee Hospital, \\ The Rochester General Hospital, and The University of Rochester School \\ of Medicine and Dentistry, Rochester, New York, U.S.A.
}

Accurate knowledge of pacemaker specifications provides the key to the understanding of complex demand pacemaker arrhythmias.

This communication describes two examples of complex pacemaker arrhythmias related to the sensing mechanism of normally functioning Medtronic demand pulse generators. Oversensing of atrial voltage generated by an atrial parasystolic focus produced the first arrhythmia. The second arrhythmia was due to partial recycling (partial sensing) of an atrial demand pacemaker by an adequate $Q R S$ signal delivered in the 'relative refractory period' of the pacemaker, a short period that follows the refractory period after the emission of the pulse.

These two cases illustrate the negligible refractory period after sensing in implantable Medtronic demand pacemakers. This feature enables such a pacemaker to detect two signals such as $P$ and $Q R S$ in quick succession.

The widespread use of demand (ventricularinhibited) pacemakers with various specifications has brought in its wake a host of new pacemaker arrhythmias. Recognition of arrhythmias stemming from normal function of a pulse generator has become increasingly complex but very important, since subtle changes in pacemaker performance may represent the earliest manifestation of pacemaker failure.

This communication describes two examples of complex pacemaker arrhythmias related to the sensing mechanism of normally functioning demand pulse generators. Examination of the electrocardiograms without precise knowledge of certain pacemaker specifications could suggest malfunction of the pulse generators.

\section{Definition of terms}

Pacemaker refractory period: period during which the demand mechanism becomes unresponsive to external or internal electrical stimulation.

A) Delivery refractory period: pacemaker refractory period following the emission of a pacing pulse.

B) Sensing refractory period: pacemaker refractory period following sensing of spontaneous electro-

Received 24 May 1971. graphic voltage or an intracardiac signal generated by external chest wall stimulation.

Partial sensing: arrhythmia with irregularly shortened escape intervals caused by incomplete discharge of the timing capacitor of a demand pacemaker (partial recycling) (Barold et al., I97I).

\section{Case reports}

Case I Fig. I and 2 show simultaneous recordings of lead II and the filtered bipolar oesophageal electrocardiogram (Barold, I97I) of an 83-yearold man the day after implantation of a transvenous 5842 Medtronic ${ }^{1}$ demand pacemaker connected to a 5819 bipolar electrode catheter ${ }^{2}$ wedged at the right ventricular apex. Initial and subsequent chest $x$-rays confirmed the anterior position of the catheter and clearly delineated the proximal electrode near the left spinal border. The spontaneous rhythm is sinus with $4: 3 \mathrm{AV}$ block. An atrial parasystolic focus with a varying degree of exit block competes with the sinus mechanism (Friedberg and Schamroth, 1970). In Fig. I (top) the inverted $P$ wave preceding the second QRS complex generates a bipolar oesophageal deflection $\left(P^{\prime}\right)$ different from the sinus deflection. The interectopic interval $\left(\mathbf{P}^{\prime} \mathbf{P}^{\prime}\right)$ in Fig. I measures $1450 \mathrm{msec}(480 \times 3)$ and $980 \mathrm{msec}$ $(490 \times 2)$ in the upper panel: $1000 \mathrm{msec}(500 \times 2)$ in the lower panel, while the interectopic interval

${ }^{1}$ Medtronic, Inc., Minneapolis, Minnesota, U.S.A.

${ }^{2}$ Medtronic, Inc. - electrodes $3.5 \mathrm{~cm}$ apart. 

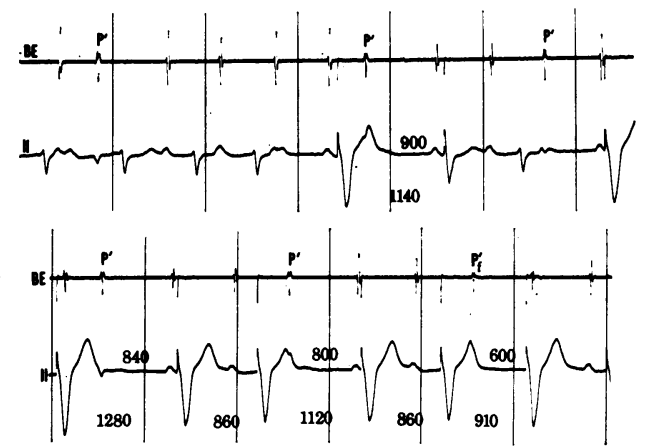

FI G. I Case I. Simultaneous recording of - filtered bipolar oesophageal electrocardiogram $(B E)$ and lead II showing sensing of atrial voltage from an atrial parasystolic focus by a 5842 Medtronic demand pacemaker. In this Figure and all subsequent ones, escape intervals in milliseconds appear above the electrocardiograms, while the intervals between two consecutive pacemaker stimuli $(E-E)$ are shown below the electrocardiograms. Escape intervals initiated by sensing of the atrial parasytolic beats $\left(P^{\prime}\right)$ are measured from the onset of the oesophageal deflections, while all other escape intervals in this paper are measured from the onset of the surface $Q R S$ or the sinus $P$ (onesecond time lines). (For full explanation, see 'text.)

in the bottom panel of Fig. 2 measures $1970 \mathrm{msec}$ $(490 \times 4)$. The timing and configuration of the last ectopic $P$ in the bottom panel of Fig. I suggests an atrial fusion beat $\left(P^{\prime} f\right)$. The automatic interval of the pacemaker is $860 \mathrm{msec}$, and measurement of numerous escape intervals following sensing of the spontaneous QRS gave an absolutely constant value of $910 \mathrm{msec}$.

The pacemaker arrhythmia is caused by the intermittent sensing of the ectopic $P$ wave voltage while the pacemaker never senses sinus $P$ waves. The origin of the arrhythmia from the sensing mechanism was confirmed by the application of the special magnet ${ }^{1}$ whereupon the arrhythmia - was completely eliminated by conversion to fixed-rate pacing. In Fig. I (top) the second $\mathrm{P}^{\prime}$ appears to recycle the pacemaker completely with an escape interval of $900 \mathrm{msec}$. The lower panel illustrates partial sensing of $P^{\prime}$ by the pacemaker, presumably because $P^{\prime}$ generates only borderline voltage to activate the demand circuit, thereby causing irregularly shortened escape intervals of

- 840, 800, and $600 \mathrm{msec}$, respectively (Barold $e t$ al., 1971). Note how $\mathrm{P}^{\prime}$ sensing may be mistaken for $\mathrm{T}$ wave sensing if the possibility of partial recycling from borderline electrographic signals is not considered. The 4 panels of Fig. 2 demonstrate varying degrees of partial $\mathrm{P}^{\prime}$ sensing. In the top

${ }^{1}$ Special magnet to actuate reed switch of 5842 Medtronic demand pacemaker.

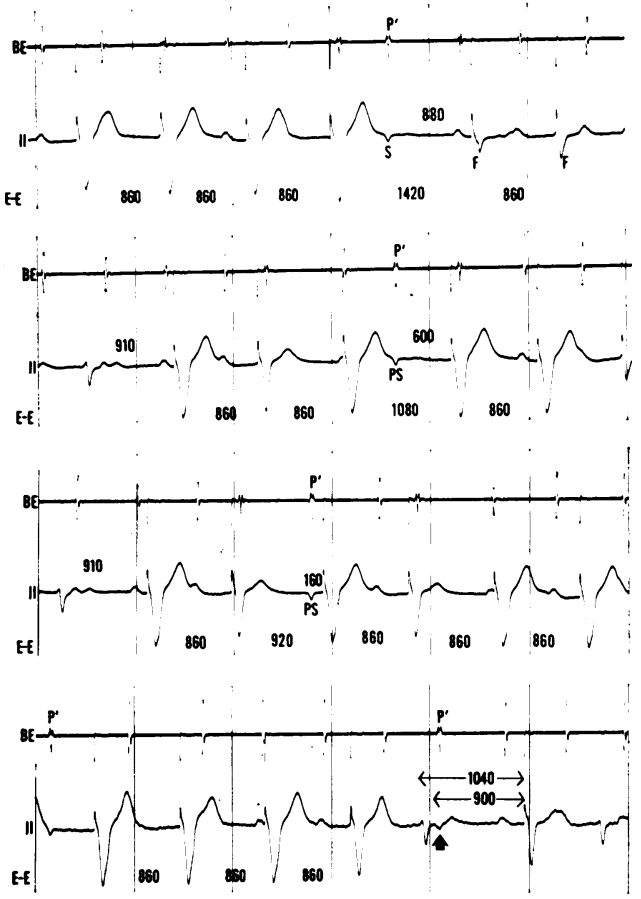

FIG. 2 Case I. Sensing of atrial parasystolic focus by a 5842 Medtronic demand pacemaker. Note in panel 4 that the pacemaker senses the $Q R S$ and $P^{\prime}$ in quick succession because its sensing refractory period is shorter than its delivery refractory period. $F=$ fusion beat, $S=$ sensed $P^{\prime}$ completely recycling the pacemaker with one complete escape interval, and $P S=$ partially sensed $P^{\prime}$ (one-second time lines). (For full explanation, see text.)

panel, $\mathbf{P}^{\prime}$ recycles the pacemaker almost completely with an escape interval of $880 \mathrm{msec}$. In the second and third panels, partial sensing of $P^{\prime}$ by the pacemaker causes short escape intervals of 600 and $160 \mathrm{msec}$, respectively.

In Fig. 2, panel 4, the interval from the onset of the first spontaneous QRS to the ensuing pacemaker spike measures ro40 $\mathrm{msec}$, because the pacemaker senses both the QRS and the ectopic P wave (arrow) deforming its ST segment 140 msec after the onset of ventricular depolarization. $P^{\prime}$ completely recycles the pacemaker with an escape interval of $900 \mathrm{msec}$. This behaviour of the sensing mechanism strongly suggests that the sensing refractory period of the pacemaker is shorter than the delivery refractory period $(200 \mathrm{msec})$, despite the inability to assess the exact electronic onset of the escape interval from the surface electrocardiogram (Barold and Gaidula, I971a).

Case 2 A 5818 bipolar electrode catheter ${ }^{1}$ connected to a 5842 Medtronic demand pacemaker

${ }^{1}$ Medtronic, Inc. - Electrodes $\mathrm{I} \cdot 5 \mathrm{~cm}$ apart. 
was permanently inserted in the coronary sinus of a 58-year-old woman with severe sinoatrial block (Kramer and Moss, 1970). The pacemaker rate was adjusted to pace the atria at 69 a minute when the PR interval (spike to onset of QRS) was 0.17 sec.

Several days after operation the pulse rate became intermittently irregular and increased up to Ioo beats a minute. Fig. 3 shows selected electrocardiographic strips of a very long recording of lead VI. Strip A, recorded at double sensitivity, shows atrial pacing at a rate of 69 a minute with a PR interval of $0.17 \mathrm{sec}$. The pacemaker completely senses each QRS and recycles with an escape interval of $700 \mathrm{msec}$. The pacemaker does not sense the first QRS in strip $B$, showing that its automatic interval measures $620 \mathrm{msec}$ (confirmed by application of the special magnet which eliminates the demand mechanism). This suggests that the delivery refractory period of the pacemaker ranges from 170 to $240 \mathrm{msec}$. The ensuing beats in strip $B$, occurring just at the end of the delivery refractory period, cause partial recycling of the pacemaker, as represented by progressively longer $\mathrm{QE}$ intervals until the fifth and sixth QRS completely recycle the pacemaker with escape intervals of $700 \mathrm{msec}$. In strip $C$ the first QRS completely recycles the pacemaker, but the second QRS initiates an oscillating sequence with unsensed QRS complexes alternating with partially sensed ones.

The demand pacemaker was inactivated by chest wall stimulation, as shown in Fig. 4 where the third and fourth chest wall stimuli inhibit the pacemaker allowing the spontaneous QRS, labelled by the arrow, to recycle the pacemaker completely with an escape interval of $700 \mathrm{msec}$. Repeated suppression of the implanted pacemaker was carried out by appropriately timed chest wall stimulation to analyse the escape interval following sensing of the spontaneous QRS. In 45 measurements taken during all phases of respiration and different body postures, the escape interval after
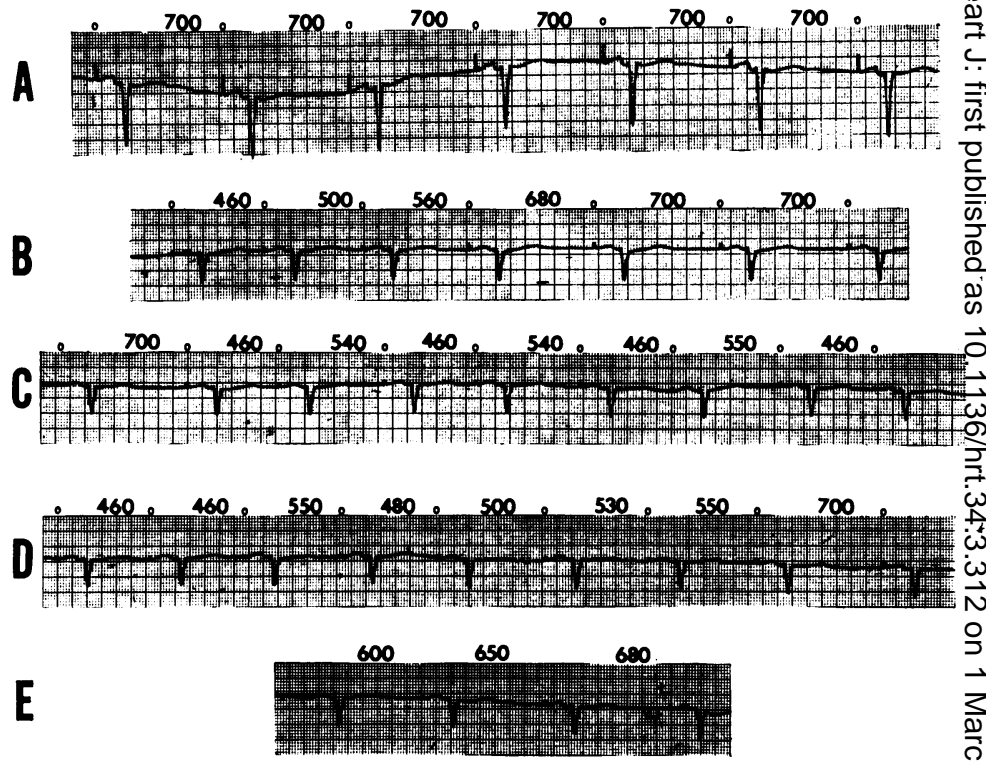

FIG. 3 Case 2. Atrial demand pacing from the coronary sinus with intermittent partial sensing of the $Q R S$ complex by 5842 Medtronic demand pacemaker. The values above the electrocardiograms are the intervals from the onset of the $Q R S$ to the ensuing pacemaker spike $(Q E)$ interval. The open circles represent pacemaker spikes. Paper speed: $50 \mathrm{~mm}$ per second. Strip $A$ was recorded at double sensitivity. (For full explanation, see text.)

sensing of the QRS complex always measured 700 msec. This finding therefore strongly suggests that the bipolar ventricular electrogram from the coronary sinus generated more than borderline

FIG. 4 Case 2. Electrocardiographic representation of the extremely short sensing refractory period of the 5842 Medtronic demand pacemaker. The open circles represent implanted pacemaker spikes, while the black squares depict external chest wall stimuli. The arrow in the first strip points to a $Q R S$ complex that completely recycles the pacemaker with an escape interval of $700 \mathrm{msec}$. (Paper speed: $50 \mathrm{~mm}$ per second.) (For full explanation, see text.)
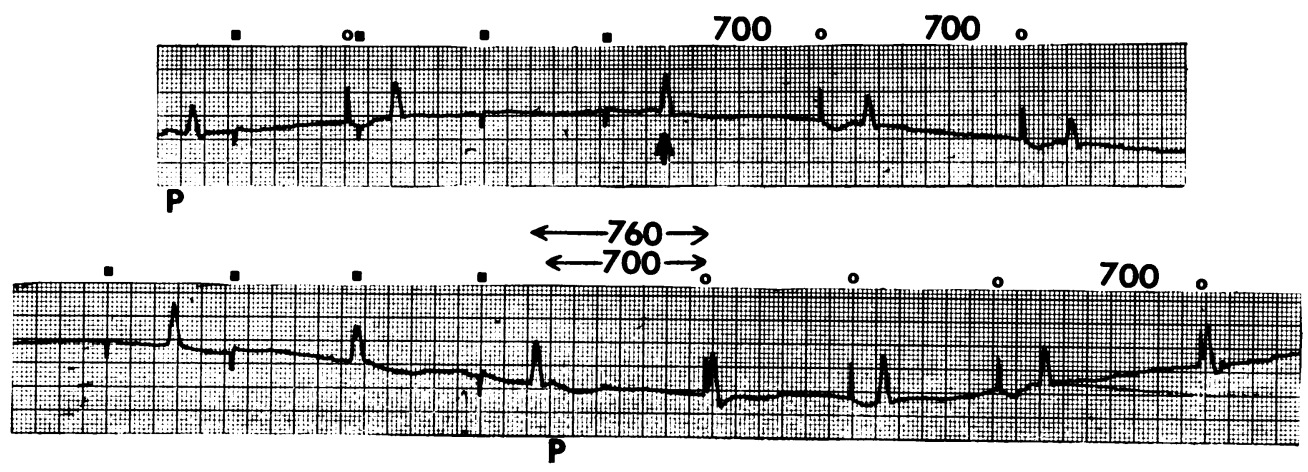
voltage for sensing, thereby excluding partial sensing from a low voltage electrogram as the mechanism for partial recycling of the pacemaker in Fig. 4 (Barold et al., 197I). In the lower strip, suppression of the pacemaker reveals the underlying slow AV junctional rhythm. A sinus $P$ wave occurs immediately after the third QRS. The interval from the onset of the third QRS to the

- next pacemaker spike measures $760 \mathrm{msec}$, while the interval from the onset of its succeeding $P$ wave to the next pacemaker spike measures 700 msec. Since repeated chest wall stimulation proved that every QRS complex falling outside the delivery refractory period of the pacemaker was capable of being sensed, these intervals show that both the $Q R S$ complex and the $P$ wave were

sensed in quick succession, a reflection of the virtually non-existent sensing refractory period of this particular pacemaker

\section{Discussion}

The interpretation of pacemaker arrhythmias originating from the sensing mechanism of a demand (ventricular-inhibited) pacemaker requires knowledge of: (I) QRS signal: unipolar ventricular electrogram in a unipolar system or bipolar electrogram in a bipolar system (Furman and Escher, 1970; Barold and Gaidula, I97Ib); (2) input sensitivity of the pacemaker commonly I to 2.5 millivolts for signals at the frequency of the ventricular electrogram (30 cycles per second); (3) duration of the escape interval in relation to the automatic interval; (4) duration of the delivery and sensing refractory periods which are not necessarily equal in all pacemakers; (5) recycling response of the pacemaker to borderline electrographic voltage for sensing (Barold $e t$ al., 1970, I97 I) and to relatively larger signals falling near the end of the delivery refractory period.

The Table presents our experience with chest wall stimulation in evaluating the clinical performance of several implanted demand pacemakers. This technique is useful because certain clinically important details of pacemaker function may not always be readily available from some manufacturers, and, indeed, some of our results, which differ from manufacturers' specifications, have helped us to understand complex pacemaker arrhythmias.

Case I represents an unusual form of oversensing atrial voltage from a parasystolic focus which, probably because of its vectorial characteristics, generated more bipolar voltage in the inflow tract of the right ventricle than normal atrial depolarization. The atrial parasystolic focus may have produced the required

TABLE Evaluation of pacemaker parameters by chest wall stimulation (Barold et al., 1970)

\begin{tabular}{|c|c|c|c|c|c|c|}
\hline $\begin{array}{l}\text { Manufacturer and model } \\
\text { number }\end{array}$ & $\begin{array}{l}\text { No. of } \\
\text { pacemakers } \\
\text { tested }\end{array}$ & $\begin{array}{l}\text { Specifications released by } \\
\text { manufacturer }\end{array}$ & $\begin{array}{l}\text { Delivery } \\
\text { refractory } \\
\text { period }\end{array}$ & $\begin{array}{l}\text { Sensing } \\
\text { refractory } \\
\text { period }\end{array}$ & $\begin{array}{l}\text { Partial } \\
\text { recycling from } \\
\text { borderline } \\
\text { stimuli }\end{array}$ & $\begin{array}{l}\text { Partial } \\
\text { recycling at } \\
\text { near end of } \\
\text { refractory } \\
\text { period }\end{array}$ \\
\hline Medtronic 5841 & IO & Not officially published & $380-455$ & $<20 \mathrm{msec}$ & Yes & Yes \\
\hline $\begin{array}{l}\text { Medtronic } 5842 \text { (old } \\
\text { generation) }\end{array}$ & IO & $\begin{array}{l}R^{\star}=150-250 \text { msec after } \\
\text { emission of pacing pulse; } \\
\text { no significant } R P \text { after sens- } \\
\text { ing spontaneous } R \text { wave }\end{array}$ & $160-260$ & $<20 \mathrm{msec}$ & Yes & Yes \\
\hline $\begin{array}{l}\text { Medtronic } 5842 \text { (new } \\
\text { generation) }\end{array}$ & 5 & $\begin{array}{l}R P=300 \pm 50 \text { msec after } \\
\text { emission of pacing pulse; no } \\
\text { significant } R P \text { after sensing } \\
\text { spontaneous } R \text { wave }\end{array}$ & $260-290 \mathrm{msec}$ & $<20 \mathrm{msec}$ & Yes & Yes \\
\hline American Optical & 2 & $\mathbf{R P}=50-100 \mathrm{msec}$ & $140 \mathrm{msec}$ & About $20 \mathrm{msec}$ & Yes & Yes \\
\hline Stanicor (Cordis) & 3 & $\begin{array}{l}\mathbf{R P}=240 \mathrm{msec} \text { after emission } \\
\text { of pacing pulse and sensing } \\
\text { of } R \text { wave }\end{array}$ & $240 \mathrm{msec}$ & $240 \mathrm{msec}$ & No & Yes \\
\hline General Electrict 2072 A & 3 & $\mathbf{R P}=50-\mathrm{r} 00 \mathrm{msec}$ & $320-410 \mathrm{msec}$ & $70-100 \mathrm{msec}$ & No & No \\
\hline
\end{tabular}

Note: The sensing refractory period of the demand pacemakers was measured by the application of $\mathrm{I}$ or $2 \mathrm{msec}$

square wave pulses delivered to the chest from a Grass $\mathbf{4} 44$ stimulator $\ddagger$ connected to a stimulus isolation and constant current units. After the response to single stimuli was recorded, one pair of identical stimuli similar in energy and duration to the single stimuli previously applied was delivered outside the delivery refractory period of the pacemakers at gradually increasing intervals of $20-300 \mathrm{msec}$.

$\star \mathbf{R P}=$ refractory period.

† The delivery refractory period of another two G.E. $2072 \mathrm{~A}$ demand pacemakers was found to be 180 and 280 msec respectively; their sensing refractory periods could not be evaluated because the spontaneous rhythm was too fast.

‡ Grass Medical Instruments, Quincy, Mass., U.S.A. 
bipolar voltage for sensing primarily from a mechanical rather than an electrical source, because of altered atrioventricular synchronization. Precise diagnosis of the complex arrhythmia in Case I is of some importance, since the arrhythmia was relatively benign and could have been eliminated with antiarrhythmic therapy to suppress the atrial parasystolic focus. Indeed, the arrhythmia had persisted in its benign form without specific antiarrhythmic therapy at the time of the last follow up six months after pacemaker implantation. The bipolar pacing catheter used in this particular patient was apparently designed by the manufacturers to avoid the possibility of low bipolar QRS signals by increasing the distance between the two electrodes to $3.5 \mathrm{~cm}$ (Barold and Gaidula, 197Ib). However, such a design favours sensing of a $\mathbf{P}$ wave, spontaneous or ectopic, either in the inflow tract of the right ventricle (Barold and Gaidula, 1971a) or near the tricuspid valve.

In some demand pacemakers the delivery and sensing refractory periods are unequal. Correct interpretation of arrhythmias due to sensing of voltage other than the QRS complex (oversensing) requires exact knowledge of the duration of the sensing refractory period to evaluate the origin of the escape interval. Since the sensing refractory period of Medtronic implanted demand pacemakers (5841, 5842, 5942, 5943) is virtually zero, such a demand pacemaker may sense two electrographic signals such as $\mathbf{P}$ and $\mathrm{QRS}$ voltage in quick succession. Such a situation may occur when epicardial electrodes are implanted near the atrioventricular groove or when the pacing catheter is in the atrium, coronary sinus, or inflow tract of the right ventricle.

We have previously reported the occurrence and mechanism of partial sensing by certain implanted demand pacemakers when artificial or spontaneous electrographic signals generate only borderline (threshold) voltage to activate the sensing circuit of these particular pacemakers outside their delivery refractory periods (Barold et al., 197I). Partial sensing may also occur when a signal of relatively high voltage occurs a few milliseconds after the end of the delivery refractory period of certain pacemakers (Table). Apparently for Medtronic implantable demand pacemakers, a relatively stronger signal is required to recycle the pacemaker completely $30-40 \mathrm{msec}$ after the end of the delivery refractory period when the amplifier is coming out of saturation (J. E. Cheatham, Medtronic Inc., 1971, personal communication). The arrhythmia in Case 2 represents a clinical manifestation of this response by a normally functioning pulse generator during its 'relative refractory period'. We have also observed partial sensing of the QRS complex by normally functioning $584 \mathrm{I}$ and 5842 Medtronic pulse generators during the 'relative refractory period' when slight intraventricular displacement of the bipolar catheter caused intermittent pacing failure with preservation of sensing because of high voltage bipolar electrograms. In this situation partial sensing occurs when the ventricular electrogram of spontaneous beats falls in the 'relative refractory period' after an ineffectual pacing stimulus.

Recent reports of the feasibility of demand atrial pacing from the right atrial appendage (Kastor et al., 1970) and the coronary sinus (Kramer and Moss, 1970) necessitate precise knowledge of pacemaker specifications. The selection of a 5842 Medtronic demand pacemaker with a delivery refractory period of 200-240 msec was unsuitable in Case 2 because slight variations of the bipolar ventricular electrogram and PR interval caused wide fluctuations in the atrial pacing rate. Therefore, we feel that demand (ventricularinhibited) pacing from the right atrium or the coronary sinus should preferably be performed by a pacemaker with a longer delivery refractory period, such as the 584I Medtronic demand pacemaker, to avoid partial or intermittent sensing of the QRS complex after paced atrial beats, or one with a very much shorter refractory period of about $100 \mathrm{msec}$, so that the QRS complex following a paced atrial beat will be consistently sensed if its ventricular electrogram generates sufficient voltage. The recently introduced new generation of 5842 (5942) and 5943 Medtronic demand pacemakers with a refractory period of $300 \pm 50 \mathrm{msec}$ could also induce the same arrhythmia from the coronary sinus as in Case 2 when the refractory period measures $250 \mathrm{msec}$ at the lower limit of the specifications, particularly when the PR interval is slightly longer than $0.17 \mathrm{msec}$. Ideally, atrial demand pacemakers should be designed with an amplifier completely insensitive to the QRS signal.

We are greatly indebted to Dr. John W. Lister of Miami Beach, who permitted us to study two of his patients with Stanicor pacemakers, and to Dr. William A. Schiess of Syracuse, who also permitted us to study three of his patients with General Electric pacemakers. The technical help provided by $\mathrm{Mr}$. Michael Carroll was invaluable.

\section{References}

Barold, S. S. (1971). Filtered bipolar esophageal electrocardiography. American Heart fournal. In the press. 
Barold, S. S., and Gaidula, J. J. (1971a). Evaluation of normal and abnormal sensing function of demand pacemakers. American fournal of Cardiology, 28, 201.

Barold, S. S., and Gaidula, J. J. (197Ib). Failure of demand pacemaker from low-voltage bipolar ventricular electrograms. Fournal of the American Medical Association, 215, 923.

Barold, S. S., Gaidula, J. J., Lyon, J. L., and Carroll, M. (197I). Irregular recycling of demand pacemakers from borderline electrographic signals. American Heart fournal, 82, 477.

Barold, S. S., Pupillo, G. A., Gaidula, J. J., and Linhart, J. W. (1970). Chest wall stimulation in evaluation of patients with implanted ventricularinhibited demand pacemakers. British Heart fournal, 32, 783 .
Friedberg, H. D., and Schamroth, L. (1970). Atrial parasystole. British Heart fournal, 32, 172.

Furman, S., and Escher, D. J. W. (1970). Principles and Techniques of Cardiac Pacing, p. 102. Harper and Row, New York and London.

Kastor, J. A., MacVaugh, H., Shelburne, J. C., and Nair, K. G. (1970). Permanent atrial pacing and sensing with curved electrodes. American fournal of Cardiology, 26, 64I.

Kramer, D. H., and Moss, A. J. (I970). Permanent pervenous atrial pacing from the coronary vein. Circulation, 42, 427.

Requests for reprints to Dr. S. Serge Barold, The Genesee Hospital, 224 Alexander Street, Rochester, New York 14607, U.S.A. 